\title{
Corrigendum: Assessing Sunscreen Lifecycle to Minimize Environmental Risk Posed by Nanoparticulate UV-Filters - A Review for Safer-by-Design Products
}

\begin{abstract}
Jérôme Labille ${ }^{1 *}$, Riccardo Catalano ${ }^{1}$, Danielle Slomberg ${ }^{1}$, Sylvie Motellier ${ }^{2}$, Annalisa Pinsino ${ }^{3}$, Pierre Hennebert ${ }^{4}$, Catherine Santaella ${ }^{5}$ and Vincent Bartolomei ${ }^{2}$

${ }^{1}$ CNRS, IRD, INRAe, Coll France, CEREGE, Aix Marseille University, Aix-en-Provence, France, ${ }^{2}$ University Grenoble Alpes, Commissariat á l'Energie Atomique et aux Energies Alternatives, DRT/LITEN/DTNM/STDC/Laboratory of Measure, Safety, and Environment, Grenoble, France, ${ }^{3}$ Istituto per la Ricerca e I'Innovazione Biomedica, Consiglio Nazionale delle Ricerche, Palermo, Italy, ${ }^{4}$ National Institute for Industrial Environment Risk (INERIS), Aix-en-Provence, France, ${ }^{5}$ Aix Marseille Univ, CEA, CNRS, BIAM, Laboratory of Microbial Ecology of the Rhizosphere, Saint-Paul-lès-Durance, France
\end{abstract}

Keywords: UV filter (sunscreen), nano risk, lifecycle, fate and transport model, safe by design, nanoparticle, environment pollution

\section{OPEN ACCESS}

Approved by:

Frontiers Editorial Office

Frontiers Media SA, Switzerland

*Correspondence: Jérôme Labille labille@cerege.fr

Specialty section: This article was submitted to

Biogeochemical Dynamics,

a section of the journal Frontiers in Environmental Science

Received: 22 August 2020

Accepted: 28 August 2020

Published: 19 October 2020

Citation: Labille J, Catalano R, Slomberg D, Motellier S, Pinsino A, Hennebert $P$, Santaella C and Bartolomei V (2020) Corrigendum: Assessing Sunscreen Lifecycle to Minimize Environmental

Risk Posed by Nanoparticulate

UV-Filters - A Review for

Safer-by-Design Products.

Front. Environ. Sci. 8:597861. doi: 10.3389/fenvs.2020.597861

\section{A Corrigendum on}

Assessing Sunscreen Lifecycle to Minimize Environmental Risk Posed by Nanoparticulate UV-Filters - A Review for Safer-by-Design Products

by Labille, J., Catalano, R., Slomberg, D., Motellier, S., Pinsino, A., Hennebert, P., et al. (2020). Front. Environ. Sci. 8:101. doi: 10.3389/fenvs.2020.00101

In the published article, there was an error in affiliations 2 and 3.

Affiliation 2: Instead of "Commissariat á l'Energie Atomique et aux Energies Alternatives, DRT/LITEN/DTNM/SEN/Laboratory of Nano-characterization and Nano-safety, 83 University of Grenoble Alpes, Grenoble, France," it should be "University Grenoble Alpes, Commissariat á l'Energie Atomique et aux Energies Alternatives, DRT/LITEN/DTNM/STDC/Laboratory of Measure, Safety, and Environment, Grenoble, France".

Affiliation 3: Instead of "University Grenoble Alpes, Commissariat á l'Energie Atomique et aux Energies Alternatives, DRT/LITEN/DTNM/STDC/Laboratory of Measure, Safety, and Environment, Grenoble, France," it should be "Istituto per la Ricerca e l'Innovazione Biomedica, Consiglio Nazionale delle Ricerche, Palermo, Italy".

The authors apologize for this error and state that this does not change the scientific conclusions of the article in any way. The original article has been updated.

Copyright $\odot 2020$ Labille, Catalano, Slomberg, Motellier, Pinsino, Hennebert, Santaella and Bartolomei. This is an open-access article distributed under the terms of the Creative Commons Attribution License (CC BY). The use, distribution or reproduction in other forums is permitted, provided the original author(s) and the copyright owner(s) are credited and that the original publication in this journal is cited, in accordance with accepted academic practice. No use, distribution or reproduction is permitted which does not comply with these terms. 